\title{
Analysis of Backbone UIN Sunan Kalijaga Network Development in Yogyakarta Using Comparison of Static Routing Protocol and OSPF Dynamic Routing
}

\author{
Rahmadhan Gatra $^{1, *}$, Bambang Sugiantoro ${ }^{1}$ \\ ${ }^{1}$ Magister Informatika, UIN Sunan Kalijaga, Indonesia \\ *Corresponding author. Email: rahmadhan.gatra@uin-suka.ac.id
}

\begin{abstract}
The development of information technology, especially computer networks, both in terms of Local Area Network (LAN) and the Internet network within the Sunan Kalijaga State Islamic University, Yogyakarta is needed to support the exchange of data or information between units, faculties, and universities. To support network development is needed a network design topology that will connect between buildings at UIN Sunan Kalijaga Yogyakarta, which uses static routing as the everapplied routing and OSPF dynamic routing as a routing protocol in the comparison of current network development. Network development is carried out in the form of modeling (simulation) using EVE-NG (Emulated Virtual Environment Next Generation). In developing the application of OSPF static and dynamic routing protocols an analysis is performed to determine the performance produced by the two routing protocols, and testing is done by using QoS parameters such as Throughput, Packet Loss, Delay, and Jitter. The test results show the value obtained between static and dynamic OSPF routing protocols with normal and busy testing scenarios include normal static protocol routing throughput of 596.82 Bps and OSPF of 598.39 Bps, while for busy scenarios using static routing protocols are 595.50 Bps and OSPF dynamic routing is 597.57 Bps. The average value for Packet loss for both routing protocols is $0 \%$. The average value of normal scenario delay protocol static routing is $59.52 \mathrm{Bps}$ and dynamic routing OSPF is $59.36 \mathrm{Bps}$, while for busy scenarios using static routing protocol is $59.65 \mathrm{Bps}$ and OSPF dynamic routing is $59.44 \mathrm{Bps}$. The value of Jitter generated from both routing is still in the range between numbers 0-75 ms. Even though the value of the comparison of the results of the tests carried out does not show a significant value, but shows that the network that implements static routing has better performance than the network that applies OSPF dynamic routing.
\end{abstract}

Keywords: LAN, OSPF, static routing, EVE-NG.

\section{INTRODUCTION}

The development of the world of information technology today is growing rapidly. It is undeniable that these developments demand speed, accuracy, and ease in accessing data and information both inside and outside an agency. The availability of the required data transmission speed will increase performance on a LAN (Local Area Network), this causes if the LAN network is interrupted it will cause everything to run abnormally or disturbed. To connect between intranet networks (inside) and the internet (outside) there is a need for network management called routing. Routing makes one of the most important parts of data communication between network devices [1].

The use of computer networks connected to the intranet and the internet that has been implemented by
UIN Sunan Kalijaga Yogyakarta has undergone several technological transformations, one of which is in terms of routing technology. Starting from the beginning of the UPT. The Computer and Information System Center in 2004 until now has become a UPT. The Center for Information Technology and Databases, UIN Sunan Kalijaga Yogyakarta has implemented several network models in terms of routing, starting from static routing with a star topology, static routing with the addition of virtual trunking protocol methods, and now implementing dynamic OSPF routing with additional virtual trunking protocol methods.

Network modeling with the application of several methods was made to keep abreast of technological developments and also to support the ease of communication and data access both faculties, units and with the outside world such as the internet. In this study, 
the author will conduct an analysis related to network development that has been applied at UIN Sunan Kalijaga Yogyakarta with a comparison of static and OSPF dynamic routing protocols.

One of the steps used in the development of computer networks is the need for a mechanism used to measure the performance of a network. A performance in a network can be measured through several parameters commonly referred to as QoS (Quality of Service) including Throughput, Packet Loss, Delay, and Jitter. These parameters are used as a benchmark to facilitate the measurement of a network performance that is being connected. In measuring network performance parameters can not make an absolute benchmark in determining the value obtained, this is because the value obtained is a value that is real-time in which the value can change at any time by network conditions at the time it worked. However, the value that has been obtained can still be used to analyze the performance of an operating network. There is research that states that QoS is one of the topics that are difficult for users to understand and is confusing in terms of data network contexts [2]. However, other studies state that using active or passive measurements will create an integrative measurement, wherewith the integrative measurement model the QoS of the network can be known [3].

This research paper compares the performance of the routing method used by UIN Sunan Kalijaga Yogyakarta before the network development using the static routing method and after the network, development using OSPF dynamic routing. It is hoped that with this research, we can find out the comparison of routing performance OSPF static and dynamic routing protocols in network development designs that implemented on the existing network at UIN Sunan Kalijaga Yogyakarta by using QoS as the measurement parameter.

\section{THEORY BASIC}

A network can be said to be connected if it has two or more network devices that communicate in one place, both using wired media or using non-wired or wireless media.

\subsection{Backbone Network}

A backbone network is the main network that connects local networks in one place to another owned by a telecommunications operator. This network must, of course, have a wide bandwidth, high transmission speed and be built with a high-reliability infrastructure [4].

\subsection{Protocol}

The protocol is a communication medium for sharing information related to networks and connections between routers that are connected using the building and improving routing tables [5]. Protocol if exemplified in its real application as in the case of verbal communication in humans, when conducting communication it is necessary to have protocols or rules that are agreed upon between people who communicate verbally so that in conducting communication can mutually understand the intended purpose and understand the purpose of delivering information it. The agreement reached can be in the use of the same language of understanding, space or place and time used when communicating. Whereas if communication is done remotely, it must be determined in advance what communication media will help in smooth communication [6].

\subsection{Routing}

Routing is a process where something can be carried from one place to another. For example, the real application of routing includes correspondence processes, transportation trips such as trains, telecommunications by telephone, and others. Whereas on a computer network there is a router device which is a network device that functions to route a network of traffic [7]. To be able to route network traffic to a router or other entity that builds routing, it is necessary to take several things into account including:

1. know the addressing of goals;

2. recognize the source of routing information from the start to the destination of the routing;

3 . determine the routes to be passed.

4. There are 2 (two) routing protocols that are often used namely static and dynamic routing with OSPF.

\subsection{Static Routing}

A routing is said to be static routing if a network administrator manages data communication paths or routes to the destination network manually [6]. Static routing is usually used for small-scale networks, but if static routing is used on a very large-scale network, it will cause the network administrator to waste time updating the routing table (SYAMSU, 2010).

\subsection{Dynamic routing}

Dynamic routing is the process of filling in the routing data in the routing table that is done automatically in a network configuration. If a network has one or more possible routes for the same destination, dynamic routing needs to be used [8]. 
Dynamic routing is intended to solve problems experienced by static routing. This dynamic routing is intended for a very large-scale network, so the network administrator is determining the routing path is no longer done manually, because the routing table has been automatically created when creating a dynamic routing itself. Therefore, dynamic routing requires a very large resource space on network devices that will be configured with dynamic routing.

There are several types of dynamic routing that are usually applied in terms of network configuration, one of which is OSPF or Open Shortest Path First. OSPF is a routing method that uses an interior routing protocol with a link-state algorithm with the following characteristics:

- Link-state routing protocols;

- Routing updates are flooded when changes in network topology occur;

- Using the SPF (Shortest Path First) algorithm to calculate the lowest cost in a network configuration.

\section{RESEARCH METHOD}

This research related to the analysis of the development of computer networks at UIN Sunan Kalijaga Yogyakarta includes several stages including:

\subsection{Study of literature}

Stages of literature studies in this study, the authors take the data conducted in several ways including carrying out the process of literature study and interviews. A literature study is conducted to explore and study further literature related to similar prior research, literature studies can be searched using both online and offline sources such as books, scientific journals, and final assignments, and so forth. While the interview is used to explore information related to the process that is being done and has been done related to research conducted by researchers.

\subsection{Needs Analysis}

Analysis of needs in a study is very important where an analysis will make the research run well by the needs and desires of a researcher. Needs analysis can be done by collecting data and information both related to hardware and software used in the area under study which will later be used to determine the performance of the use of these devices, which in this case concerns the performance of OSPF static and dynamic routing that has been and is being implemented by UIN Sunan Kalijaga Yogyakarta in terms of network development.

\subsection{Designing computer network development needs}

The design is the initial stage used in building and developing a computer network. The design was built to minimize errors in the construction and development of a computer network. At this stage, a network design model will be produced which will be tested based on test scenarios under normal and busy conditions.

\subsection{Modeling the needs of computer network development}

Modeling is a follow-up of the design stages in building and developing computer networks. In this study, researchers will do network modeling using the EVE-NG (Emulated Virtual Environment Next Generation) simulator. This modeling stage is carried out to minimize the cost and damage aspects that can be caused by network hardware caused by both human factors and natural factors.

\subsection{Testing}

Testing is needed to find out how effective and efficient the network modeling design has been made before. By testing, it can find out the performance of a computer network. Testing can be done with several kinds of them by using the PING command in the command prompt application. PING command is done by sending an ICMP protocol on a computer to other computers that are destined for a network. Then an analysis of the measurement results of each parameter is tested. The quality of these results can be written in the form of Throughput, Packet loss, Delay and Jitter values for each QoS tested.

\subsection{QoS Testing Parameters}

QoS is a technique for managing the performance of predetermined parameters such as bandwidth, delay, jitter, and packet loss for flow in the network. The purpose of the QoS mechanism is to affect at least one of the four predetermined QoS parameters. QoS is used to help network administrators optimize the network of connected computers. Some QoS testing parameters used in performance measurement on computer networks include the following:

\section{Throughput}

Throughput is the total packet received successfully by destination in a network during a certain interval divided by the time interval of the duration of the data packet transmission. Speed (rate) of effective data transfer measured in the form of bps (bits per second). Throughput can be calculated using the Equation (1):

Throughput $=\frac{\text { amount of data sent }}{\text { time of sending data }}$ 


\section{Packet Loss}

Packet loss is a parameter that describes a condition that shows the total number of packets lost. Packet loss can occur due to a collision and congestion on a network. To calculate packet loss you can use the Equation (2):

Packet loss $=$
$\frac{\text { Data packet sent }- \text { data packet received }}{\text { Data packet sent }} \times 100 \%$

The value categories of a packet loss can be seen in Table 1.

Table 1. List of Packet Loss Categories

\begin{tabular}{|c|c|c|}
\hline Value & Percentage & Index \\
\hline 4 & 0 & Excellent \\
\hline 3 & 3 & Good \\
\hline 2 & 15 & Medium \\
\hline 1 & 25 & Poor \\
\hline
\end{tabular}

3. Delay

Delay is the time taken by the packet to arrive at its destination from the time the first bit is sent out from the source. For total delay it can be calculated using Equation (3):

Total delay $=\sum$ Time packet received time package sent

While to calculate the average delay can use Equation (4):

Average delay $=\frac{\text { total delay }}{\text { total packet delivery }}$

Based on the results of the calculation of the equation looking for the delay formula, the resulting category value can be seen in Table 2 .

Table 2. List of Delay Categories

\begin{tabular}{|c|c|c|}
\hline Value & Delay (ms) & Index \\
\hline 4 & $<150$ & Excellent \\
\hline 3 & $150-300$ & Good \\
\hline 2 & $300-450$ & Medium \\
\hline 1 & $>450$ & Poor \\
\hline
\end{tabular}

4. Jitter

Jitter in the QoS parameter is a variation of delay in the queue length of packets received. Jitter is also closely related to latency which addresses the amount of delay that occurs in the data transmission of a network. Jitter can be calculated using Equation (5):

Jitter $=\frac{\text { total delay variation }}{\text { total packet receive }}$

While to calculate the total variation of delay can use Equation (6):

Total delay variation $=$ delay (average delay)

Based on the calculation results of the equation looking for jitter, the resulting category values can be seen in Table 3.

\section{COMPUTER NETWORK TOPOLOGY}

In the development of computer network development in UIN Sunan Kalijaga Yogyakarta, there have been many changes in the implementation of routing. The development of the network topology at UIN Sunan Kalijaga Yogyakarta can be seen in Figure 1 and Figure 2.

Table 3. List of Jitter Categories

\begin{tabular}{|c|c|c|}
\hline Value & Jitter $(\mathbf{m s})$ & Index \\
\hline 4 & 0 & Excellent \\
\hline 3 & $0-75$ & Good \\
\hline 2 & $75-125$ & Medium \\
\hline 1 & $125-225$ & Poor \\
\hline
\end{tabular}

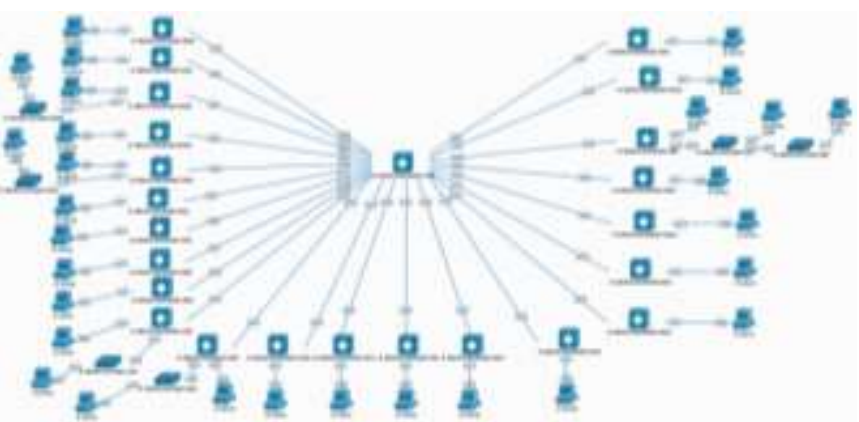

Figure 1 Star topology using static routing of UIN Sunan Kalijaga Yogyakarta

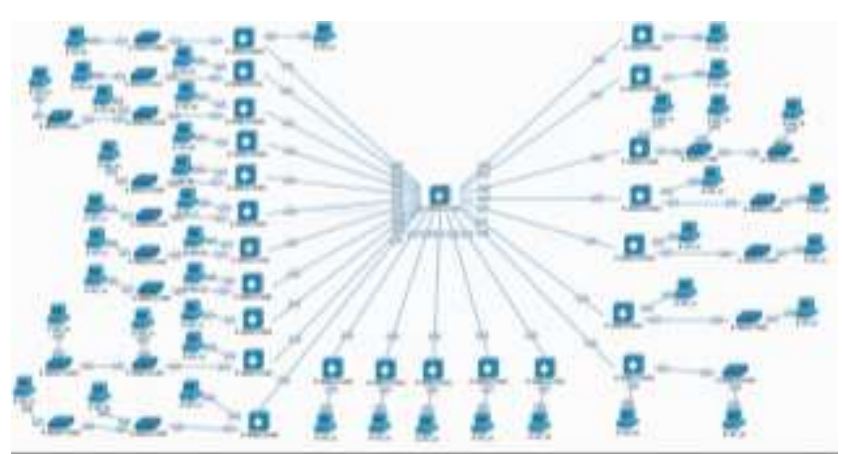

Figure 2 Star topology using dynamic routing OSPF UIN Sunan Kalijaga Yogyakarta

\section{RESULTS AND DISCUSSION}

After modeling the topology design and configuration of all connected devices, the next step is to test pre-determined routing. This testing phase is carried out by taking samples of several building units and faculties that have represented the scientific field and the intensity of the use of computer network connections. Among the samples taken can be seen in Table 4.

After making the stages of determining the connection sample that will be tested in network modeling (simulation) using the EVE-NG application, the next step is to take measurements or tests to produce a value by predetermined QoS parameters. 
Table 4. List of sample routing data collection zones

\begin{tabular}{|c|l|ll|}
\hline No & $\begin{array}{c}\text { Group } \\
\text { Name / } \\
\text { Zone }\end{array}$ & \multicolumn{2}{|l|}{ Location Building Name } \\
\hline 1 & Zone Unit & $\begin{array}{l}\text { New Rectorate } \\
\text { Integrated Laboratory } \\
\text { library }\end{array}$ \\
\hline 2 & $\begin{array}{l}\text { Strata 1 } \\
\text { Faculty Zone }\end{array}$ & $\begin{array}{l}\text { Faculty of Social Sciences } \\
\text { and Humanities } \\
\text { Faculty of Science and } \\
\text { Technology } \\
\text { Faculty of Usuluddin and } \\
\text { Islamic Thought }\end{array}$ \\
\hline 3 & $\begin{array}{l}\text { Strata 2 and 3 } \\
\text { Postgraduate } \\
\text { Zone }\end{array}$ & $\begin{array}{l}\text { Postgraduate Masters and } \\
\text { Doctoral Programs }\end{array}$ \\
\hline
\end{tabular}

\subsection{Throughput Results and Analysis}

Equation (1) is used to find the value of the throughput made during measurement. The results of testing the throughput parameters with two scenarios using static routing and dynamic OSPF routing can be seen in Table 5 and Table 6.

Table 5. Test results throughput for static routing

\begin{tabular}{|c|c|c|c|}
\hline \multicolumn{2}{|c|}{ Static Normal Scenario } & \multicolumn{2}{|c|}{ Static Busy Scenario } \\
\hline $\begin{array}{c}\text { Data Packet } \\
\text { ICMP } \\
\text { (Bytes) }\end{array}$ & Average & $\begin{array}{c}\text { Data Packet } \\
\text { ICMP } \\
\text { (Bytes) }\end{array}$ & Average \\
\hline 100 & 143.11 & 100 & 142.77 \\
\hline 200 & 244.15 & 200 & 243.42 \\
\hline 300 & 344.61 & 300 & 344.09 \\
\hline 400 & 445.78 & 400 & 444.59 \\
\hline 500 & 546.48 & 500 & 545.09 \\
\hline 600 & 647.53 & 600 & 645.61 \\
\hline 700 & 747.80 & 700 & 746.38 \\
\hline 800 & 849.07 & 800 & 847.20 \\
\hline 900 & 949.55 & 900 & 947.89 \\
\hline 1000 & 1050.13 & 1000 & 1047.99 \\
\hline $\begin{array}{c}\text { Average } \\
\text { Total }\end{array}$ & $\mathbf{5 9 6 . 8 2}$ & $\begin{array}{c}\text { Average } \\
\text { Total }\end{array}$ & $\mathbf{5 9 5 . 5 0}$ \\
\hline
\end{tabular}

Based on Table 5 and Table 6 for the throughput parameters generated between normal and busy scenarios on both static routing protocols and OSPF dynamic routing can be presented in the graph in Figure 3. In this graph, it can be seen that the values for the outcome parameters of the static routing protocol either use scenarios Normal or busy scenarios are lower than using OSPF dynamic routing.
Table 6. Test results throughput for OSPF dynamic routing

\begin{tabular}{|c|c|c|c|}
\hline \multicolumn{2}{|c|}{$\begin{array}{c}\text { OSPF Normal } \\
\text { Scenario }\end{array}$} & \multicolumn{2}{c|}{ OSPF Busy Scenario } \\
\hline $\begin{array}{c}\text { Data Packet } \\
\text { ICMP } \\
\text { (Bytes) }\end{array}$ & $\begin{array}{c}\text { Averag } \\
\mathrm{e}\end{array}$ & $\begin{array}{c}\text { Data Packet } \\
\text { ICMP (Bytes) }\end{array}$ & $\begin{array}{c}\text { Averag } \\
\mathrm{e}\end{array}$ \\
\hline 100 & 143.57 & 100 & 143.28 \\
\hline 200 & 244.57 & 200 & 244.26 \\
\hline 300 & 345.65 & 300 & 345.21 \\
\hline 400 & 446.85 & 400 & 446.30 \\
\hline 500 & 547.98 & 500 & 547.01 \\
\hline 600 & 648.93 & 600 & 647.93 \\
\hline 700 & 750.04 & 700 & 749.14 \\
\hline 800 & 851.09 & 800 & 849.90 \\
\hline 900 & 951.85 & 900 & 950.87 \\
\hline 1000 & 1053.4 & 1000 & 1051.84 \\
\hline $\begin{array}{c}\text { Average } \\
\text { Total }\end{array}$ & $\mathbf{5 9 8 . 3 9}$ & $\begin{array}{c}\text { Average } \\
\text { Total }\end{array}$ & $\mathbf{5 9 7 . 5 7}$ \\
\hline
\end{tabular}

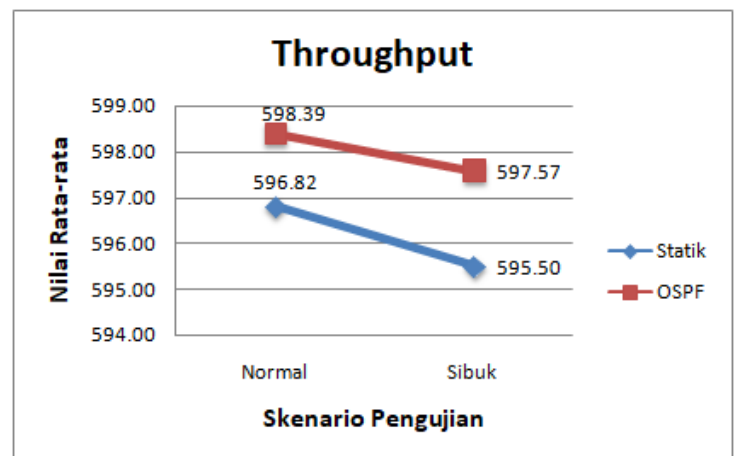

Figure 3. Graphs of average performance of static routing throughput and OSPF dynamic routing

\subsection{Results and Analysis of Packet loss}

Equation (2) is used to find the percentage of Packet loss values. The results of testing on packet loss parameters with two scenarios using static routing and dynamic OSPF routing can be seen in Table 7 and Table 8.

Based on Table 7 and Table 8 for packet loss parameters generated between normal and busy scenarios on both static routing protocols and OSPF dynamic routing can be presented in the graph in Figure 4. In this graph, it can be seen that the values for the outcome parameters of the Static protocol either use scenarios Normal or busy scenarios are lower than using OSPF dynamic routing.

\subsection{Delay Results and Analysis}

In finding the value of delay and the average delay can use Equations (3) and (4). The results of testing the delay parameters with two scenarios using static routing 
and OSPF dynamic routing can be seen in Table 9 and Table 10.

Table 7. Test results packet loss for static routing

\begin{tabular}{|c|c|c|c|}
\hline \multicolumn{2}{|c|}{$\begin{array}{c}\text { Static Normal } \\
\text { Scenario }\end{array}$} & \multicolumn{2}{c|}{ Static Busy Scenario } \\
\hline $\begin{array}{c}\text { Data } \\
\text { Packet } \\
\text { ICMP } \\
\text { (Bytes) }\end{array}$ & Average & $\begin{array}{c}\text { Data Packet } \\
\text { ICMP } \\
\text { (Bytes) }\end{array}$ & Average \\
\hline 100 & 0.24 & 100 & 0.23 \\
\hline 200 & 0.25 & 200 & 0.23 \\
\hline 300 & 0.24 & 300 & 0.23 \\
\hline 400 & 0.24 & 400 & 0.23 \\
\hline 500 & 0.24 & 500 & 0.23 \\
\hline 600 & 0.24 & 600 & 0.23 \\
\hline 700 & 0.24 & 700 & 0.23 \\
\hline 800 & 0.24 & 800 & 0.23 \\
\hline 900 & 0.24 & 900 & 0.23 \\
\hline 1000 & 0.24 & 1000 & 0.23 \\
\hline $\begin{array}{c}\text { Average } \\
\text { Total }\end{array}$ & $\mathbf{0 . 2 4}$ & $\begin{array}{c}\text { Average } \\
\text { Total }\end{array}$ & $\mathbf{0 . 2 3}$ \\
\hline
\end{tabular}

Table 8. Test results routing packet loss for OSPF dynamic routing

\begin{tabular}{|c|c|c|c|}
\hline \multicolumn{2}{|c|}{$\begin{array}{c}\text { OSPF Normal } \\
\text { Scenario }\end{array}$} & \multicolumn{2}{c|}{ OSPF Busy Scenario } \\
\hline $\begin{array}{c}\text { Data } \\
\text { Packet } \\
\text { ICMP } \\
\text { (Bytes) }\end{array}$ & Average & $\begin{array}{c}\text { Data Packet } \\
\text { ICMP } \\
\text { (Bytes) }\end{array}$ & Average \\
\hline 100 & 0.27 & 100 & 0.27 \\
\hline 200 & 0.27 & 200 & 0.26 \\
\hline 300 & 0.27 & 300 & 0.26 \\
\hline 400 & 0.27 & 400 & 0.26 \\
\hline 500 & 0.26 & 500 & 0.26 \\
\hline 600 & 0.27 & 600 & 0.26 \\
\hline 700 & 0.27 & 700 & 0.26 \\
\hline 800 & 0.27 & 800 & 0.26 \\
\hline 900 & 0.27 & 900 & 0.26 \\
\hline 1000 & 0.27 & 1000 & 0.26 \\
\hline $\begin{array}{c}\text { Average } \\
\text { Total }\end{array}$ & $\mathbf{0 . 2 7}$ & $\begin{array}{c}\text { Average } \\
\text { Total }\end{array}$ & $\mathbf{0 . 2 6}$ \\
\hline
\end{tabular}

Based on Table 9 and Table 10 for the delay parameters generated between normal and busy scenarios in both static routing protocols and OSPF dynamic routing can be presented in the graph in Figure 5. In this graph, it can be seen that the values for the parameters resulting from OSPF dynamic routing both use scenarios normal or busy scenarios are lower than using static routing protocols.

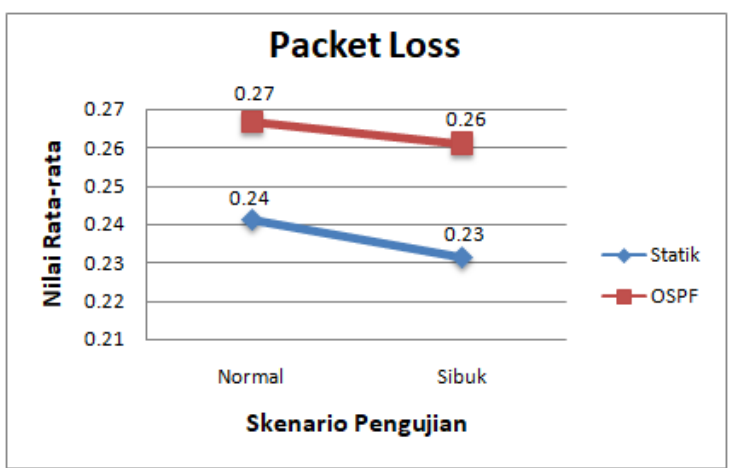

Figure 4. Graphs of average performance of static routing packet loss routing and OSPF dynamic routing Table 9. Test results delay for static routing

\begin{tabular}{|c|c|c|c|}
\hline \multicolumn{2}{|c|}{ Static Normal Scenario } & \multicolumn{2}{c|}{ Statik Busy Scenario } \\
\hline $\begin{array}{c}\text { Data Packet } \\
\text { ICMP (Bytes) }\end{array}$ & $\begin{array}{c}\text { Averag } \\
\mathrm{e}\end{array}$ & $\begin{array}{c}\text { Data Packet } \\
\text { ICMP } \\
\text { (Bytes) }\end{array}$ & $\begin{array}{c}\text { Averag } \\
\mathrm{e}\end{array}$ \\
\hline 100 & 59.54 & 100 & 59.68 \\
\hline 200 & 59.47 & 200 & 59.65 \\
\hline 300 & 59.55 & 300 & 59.64 \\
\hline 400 & 59.49 & 400 & 59.65 \\
\hline 500 & 59.51 & 500 & 59.66 \\
\hline 600 & 59.49 & 600 & 59.67 \\
\hline 700 & 59.54 & 700 & 59.65 \\
\hline 800 & 59.5 & 800 & 59.63 \\
\hline 900 & 59.53 & 900 & 59.63 \\
\hline 1000 & 59.54 & 1000 & 59.66 \\
\hline $\begin{array}{c}\text { Average } \\
\text { Total }\end{array}$ & $\mathbf{5 9 . 5 2}$ & $\begin{array}{c}\text { Average } \\
\text { Total }\end{array}$ & $\mathbf{5 9 . 6 5}$ \\
\hline
\end{tabular}

Table 10. Test results delay for OSPF dynamic routing

\begin{tabular}{|c|c|c|c|}
\hline \multicolumn{2}{|c|}{$\begin{array}{c}\text { OSPF Normal } \\
\text { Scenario }\end{array}$} & \multicolumn{2}{c|}{ OSPF Busy Scenario } \\
\hline $\begin{array}{c}\text { Data Packet } \\
\text { ICMP } \\
\text { (Bytes) }\end{array}$ & $\begin{array}{c}\text { Averag } \\
\text { e }\end{array}$ & $\begin{array}{c}\text { Data Packet } \\
\text { ICMP } \\
\text { (Bytes) }\end{array}$ & $\begin{array}{c}\text { Averag } \\
\text { e }\end{array}$ \\
\hline 100 & 59.35 & 100 & 59.47 \\
\hline 200 & 59.37 & 200 & 59.44 \\
\hline 300 & 59.37 & 300 & 59.44 \\
\hline 400 & 59.35 & 400 & 59.42 \\
\hline 500 & 59.35 & 500 & 59.45 \\
\hline 600 & 59.36 & 600 & 59.45 \\
\hline 700 & 59.36 & 700 & 59.43 \\
\hline 800 & 59.36 & 800 & 59.44 \\
\hline 900 & 59.38 & 900 & 59.44 \\
\hline 1000 & 59.35 & 1000 & 59.44 \\
\hline $\begin{array}{c}\text { Average } \\
\text { Total }\end{array}$ & $\mathbf{5 9 . 3 6}$ & $\begin{array}{c}\text { Average } \\
\text { Total }\end{array}$ & $\mathbf{5 9 . 4 4}$ \\
\hline
\end{tabular}




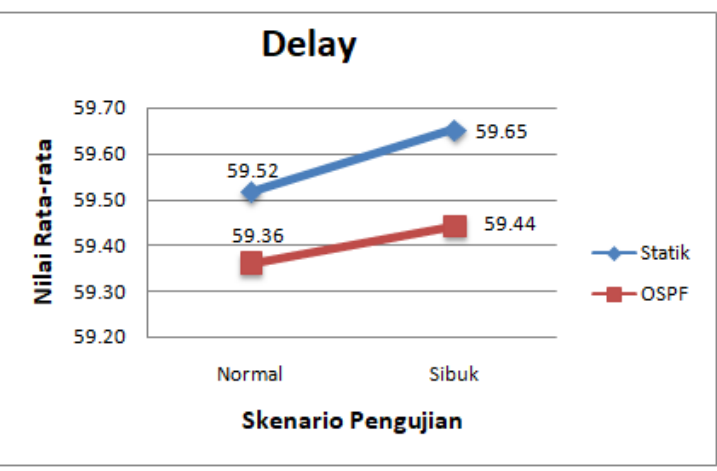

Figure 5. Graphs of average performance of static routing delay routing and OSPF dynamic routing

\subsection{Jitter Results and Analysis}

Equations (5) and (6) are used to find the value of jitter and the total delay variation. The results of testing the jitter parameters with two scenarios using static routing and OSPF dynamic routing can be seen in Table 11 and Table 12.

Table 11. Test results jitter for static routing

\begin{tabular}{|c|c|c|c|}
\hline \multicolumn{2}{|c|}{$\begin{array}{c}\text { Static Normal } \\
\text { Scenario }\end{array}$} & \multicolumn{2}{c|}{ Statik Busy Scenario } \\
\hline $\begin{array}{c}\text { Data Packet } \\
\text { ICMP } \\
\text { (Bytes) }\end{array}$ & Average & $\begin{array}{c}\text { Data Packet } \\
\text { ICMP } \\
\text { (Bytes) }\end{array}$ & Average \\
\hline 100 & 0.98 & 100 & 0.98 \\
\hline 200 & 0.98 & 200 & 0.98 \\
\hline 300 & 0.98 & 300 & 0.98 \\
\hline 400 & 0.98 & 400 & 0.98 \\
\hline 500 & 0.98 & 500 & 0.98 \\
\hline 600 & 0.98 & 600 & 0.98 \\
\hline 700 & 0.98 & 700 & 0.97 \\
\hline 800 & 0.98 & 800 & 0.98 \\
\hline 900 & 0.98 & 900 & 0.97 \\
\hline 1000 & 0.98 & 1000 & 0.97 \\
\hline $\begin{array}{c}\text { Average } \\
\text { Total }\end{array}$ & $\mathbf{0 . 9 8}$ & $\begin{array}{c}\text { Average } \\
\text { Total }\end{array}$ & $\mathbf{0 . 9 8}$ \\
\hline
\end{tabular}

Based on Table 11 and Table 12 for the jitter parameters generated between normal and busy scenarios in the two routing protocols can be presented in the graph in Figure 6. In this graph, it can be seen that the values for the result parameters of both routing using normal scenarios are relatively the same but in the scenario, busy dynamic routing OSPF is higher than using static routing protocols.

\section{CONCLUSION}

Based on the results of throughput testing, it can be produced that the value of throughput for static routing is smaller than the throughput that exists in OSPF dynamic routing. While the delay value performed using EVE-NG software for star network topology simulation found that the results of the delay when testing using static routing with normal conditions amounted to $59.52 \mathrm{Bps}$, while using dynamic OSPF routing with normal conditions amounted to $59.36 \mathrm{Bps}$. In a busy condition, the delay value for static routing is $59.65 \mathrm{Bps}$, and dynamic routing for OSPF is 59.44 Bps so that the greater delay is required by a device in the network to deliver packets on the routing will cause network performance will also getting worse.

Table 12. Test results jitter for OSPF dynamic routing

\begin{tabular}{|c|c|c|c|}
\hline \multicolumn{2}{|c|}{$\begin{array}{c}\text { OSPF Normal } \\
\text { Scenario }\end{array}$} & \multicolumn{2}{c|}{ OSPF Busy Scenario } \\
\hline $\begin{array}{c}\text { Data Packet } \\
\text { ICMP } \\
\text { (Bytes) }\end{array}$ & Average & $\begin{array}{c}\text { Data Packet } \\
\text { ICMP } \\
\text { (Bytes) }\end{array}$ & Average \\
\hline 100 & 0.98 & 100 & 0.99 \\
\hline 200 & 0.98 & 200 & 0.99 \\
\hline 300 & 0.98 & 300 & 0.99 \\
\hline 400 & 0.98 & 400 & 0.99 \\
\hline 500 & 0.98 & 500 & 0.99 \\
\hline 600 & 0.98 & 600 & 0.99 \\
\hline 700 & 0.98 & 700 & 0.99 \\
\hline 800 & 0.98 & 800 & 0.99 \\
\hline 900 & 0.98 & 900 & 0.99 \\
\hline 1000 & 0.98 & 1000 & 0.99 \\
\hline $\begin{array}{c}\text { Average } \\
\text { Total }\end{array}$ & $\mathbf{0 . 9 8}$ & $\begin{array}{c}\text { Average } \\
\text { Total }\end{array}$ & $\mathbf{0 . 9 9}$ \\
\hline
\end{tabular}

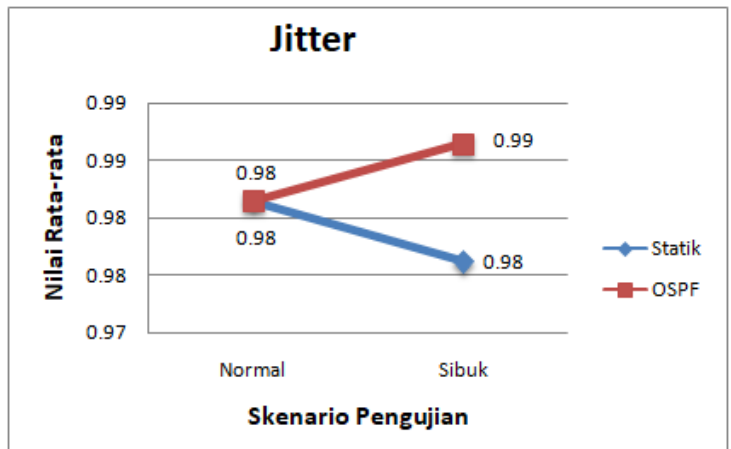

Figure 6. Graph of average performance of static routing jitter and OSPF dynamic routing

For the average total value of the jitter, a parameter is still very good in the range ranging from $0-75 \mathrm{~ms}$ for both routing protocols performed and packet loss in this test using static routing and OSPF dynamic routing produces a value that is still the same that is $0 \%$. So it can be concluded that both routings are still very good in terms of packet delivery to their destination.

Sending a data packet cannot be assessed absolutely because in the case of sending it depends on 
how much the data packet is sent and received and the amount of bandwidth needed to send and receive data packets, so that sometimes the data packet will quickly arrive at reception at the destination and sometimes the data packet is slow to reach the destination.

Based on the results of the measurements that have been carried out in this study, the results are that: Networks by implementing static routing protocols have better performance than OSPF dynamic routing and as a routing protocol that is recommended for the development of a computer network.

\section{REFERENCES}

[1] M. Muhallim, "Pengembangan Jaringan Komputer Universitas Andi Djemma Palopo Berdasarkan Perbandingan Jaringan Protokol Routing Statik dan OSPFv2," vol. 2, pp. 89-99, 2017.

[2] P. Ferguson and G. Huston, Quality of Service on the Internet: Fact, Fiction, or Compromise?, no. January. 1998.

[3] W. Sugeng, J. E. Istiyanto, K. Mustofa, and A. Ashari, "The Impact of QoS Changes towards Network Performance," Int. J. Comput. Networks Commun. Secur., vol. 3, no. 2, pp. 48-53, 2015, [Online].

Available: http://www.ijcncs.org/published/volume3/issue2 /p5_3-2.pdf.

[4] J. B. S. Sibarani and M. Zulfin, "( Backbone ) Menggunakan Serat Optik Di Universitas Sumatera Utara," J. Sigunda Ensikom, vol. 4, pp. 94-99, 2013.

[5] A. Basith, "Optimalisasi Jaringan Topologi Star Dengan Algoritma Link-State Menggunakan Model Simulasi Graphical Network Simulator 3," vol. 11, no. 2, pp. 10-14, 2011, doi: 10.16194/j.cnki.31-1059/g4.2011.07.016.

[6] L. R. Argenta, "Analisis Unjuk Kerja RIP dan OSPF pada Topologi Sederhana dan Topologi Kompleks," Universitas Sanata Dharma Yogyakarta, 2016.

[7] A. P. N. Permana and R. Firmansyah, "Distribusi Jaringan Menggunakan Routing OSPF Dengan Metode Redistribution," Simetris J. Tek. Mesin, Elektro dan Ilmu Komput., vol. 9, no. 1, pp. 519532, 2018, doi: 10.24176/simet.v9i1.2030.

[8] Achmad, "Implementasi Routing Protocol Open Shortest Path First ( OSPF ) Pada Model Topology Ring," Fakt. Exacta, vol. 8, no. 2, pp. 92-99, 2015, doi: http://dx.doi.org/10.30998/faktorexacta.v8i2.314 